\title{
Nasal fractures and anesthetic applications
}

\author{
Neslihan SARI (D) \\ ${ }^{1}$ Otolaryngology Clinic, Mardin Training and Research Hospital, Mardin, Turkey. \\ Corresponding Author: Neslihan SARI \\ E-mail: neslihansari@artuklu.edu.tr
}

Submitted: 23.05.2021 Accepted: 17.10 .2021

\begin{abstract}
Objective: The aim of this study was to review and compare the demographic characteristics, radiological findings, pain scores and the level of satisfaction of patients who underwent nasal fracture reduction (NFR) under sedation anesthesia (SA), infiltrative anesthesia (IA) or topical anesthesia (TA).

Patients and Methods: Sixty patients were included in the study according to the types of anesthesia applied: SA group, IA group and TA group. Demographic data (age, gender, etiology, duration and time to NFR), radiological findings (presence of septal fracture, hematoma), pain scores, nasal patency and cosmetic satisfaction levels were analyzed.

Results: The mean age of patients was $23.8 \pm 19.3$. The mean age of females was 23 (38.3\%) and mean age of males was 37 (61.7\%). The mean age of the SA group was $6.1 \pm 4$. The most common etiology was falls, (39 patients $65 \%$ ). Duration of the operation was higher in patients (TA group) who had closed reduction. Pain score was lowest at 0 hour in the IA group (open reduction), while it was lowest at 48 hours in the TA group. Cosmetic satisfaction level was high in the SA group $(\mathrm{p}<0.05)$. Septal fracture was detected in $95 \%$ of the patients and septal hematoma in $36 \%$ of the patients in tomographic evaluation.

Conclusion: Sedation anesthesia was applied mostly to children, whereas, IA and TA were mostly applied to adult patients due to patient compliance. Short operation time and immediate pain control were advantages of IA.TA was preferred when cosmetic expectations were low in adults. Septal fracture and hematoma that cause nasal deformations, frequently seen in nasal fracture, may be missed by physical examination but can easily be detected by tomographic examination, but the risks of tomography should be noted.

Keywords: Demographic, Anesthesia, Pain, Fracture reduction, Satisfaction.
\end{abstract}

\section{INTRODUCTION}

Nasal Fracture (NF) is a frequently encountered emergency in daily clinical practice of the Ear, Nose Throat (ENT) and Plastic Surgery services [1], and it accounts for 39 to $45 \%$ of all facial bone fractures [2]. There are several different interventions utilized in nasal fracture reduction (NFR). These interventions are closed reduction (CR), which does not include any incision technique on one end of the spectrum, and the other one is open reduction $(\mathrm{OR})$ at the other end, and this involves septoplasty and rhinoplasty techniques [3]. CR is usually carried out via blind techniques using manual manipulation or various instruments, such as the Asch and Walsham forceps. These interventions aim to fix the fractured segment of bone without direct view under the overlying mucoperichondrium $[1,4]$. Although, CR generally provides acceptable outcomes, OR can facilitate better cosmetic and functional outcomes [5].

Since, NFR is a painful procedure, anesthesia is necessary regardless of CR or OR treatment [6]. Almost all types of anesthesia could be used in NFR, including general anesthesia (GA), sedation anesthesia (SA), infiltrative anesthesia (IA) and topical anesthesia (TA). These approaches result in different levels of sedation and anesthesia as a continuum from minimal sedation (anxiolysis) to moderate sedation, to deep sedation, and to complete GA [7]. In GA, the airway should be safely opened and complete loss of consciousness must be maintained;

How to cite this article: Sari N. Nasal fractures and anesthetic applications. Marmara Med J 2022; 35(1):107-114. doi: 10.5472/marumj.1065843 
therefore, oropharyngeal bleeding and aspiration can be easily manipulated. In SA, intubation is not needed and there are some other advantages such as effective analgesia, adequate anxiolysis, short hospital stay and early awakening. Although, IA and TA allow to carry out surgery without the need for intubation or mechanical ventilation, anxiety-related to the procedure and the presence of some pain are their disadvantages [8]. The aim of this study was to provide an overview of NFR by examining demographic characteristics and radiological findings, pain scores and satisfaction levels in patients who underwent NFR with the use of SA, IA and TA.

\section{PATIENTS and METHODS}

Three hundred and twenty-five NF patients were evaluated in a secondary care hospital from $1^{\text {st }}$ December 2018 to $1^{\text {st }}$ August, 2020.The study was conducted in accordance with the ethical principles stated in the Declaration of Helsinki and was approved by the Ethics Committee for Clinical Research at Gazi Yasargil Education and Research Hospital (REF: 2019/392). Institutional ethics committee approval was obtained before commencing to collect the data. Informed consent was obtained from all participants before NFR.

Inclusion criteria were: patients who had a computed tomography (CT) scan with head trauma or various suspicious trauma to head and face region, as well as having a radiologic evaluation only with isolated nasal trauma. Exclusion criteria were: those with additional maxillofacial trauma, those with major comorbidities (cancer, metabolic diseases, chronic diseases), those with elevated liver and kidney function tests and those with coagulation or blood disorders.

Sixty patients who underwent NFR were divided into three groups according to the types of anesthesia applied (SA, IA or TA). Each group consisted of 20 patients, and these were selected randomly. The pain scores and satisfaction levels in each group were assessed. In otolaryngological examination of 60 patients; 4 of the patients had epistaxis. Twelve patients had an overt nasal deformity and 44 patients had nasal obstruction due to deviated septum and blood clots in the nasal passages. NF type was classified with the Stranc-Robertson classification [9] (Table I). Other otolaryngological findings were found to be normal. Age, gender, cause of nasal fracture, duration of operation, reduction time, re-operation requirements were recorded from the clinical and operation notes of patients. The characteristics of the septal fracture and the presence/absence of septal hematoma were recorded by analyzing the CT of patients (Table II).

\section{Anesthesia Procedures}

In the SA group, $1.5 \mathrm{~L} / \mathrm{min}$ of oxygen was administered using an oral oxygen canula. The loading dose was intravenous (IV) ketamine (1-2 mg/kg), midazolam (0.05-0.1 mg/kg), fentanyl $(1-2 \mathrm{mcg} / \mathrm{kg})$ or propofol $(0.5-1 \mathrm{mg} / \mathrm{kg})$. This administration could be increased gradually by $0.5-\mathrm{mg} / \mathrm{kg}$ [10]. In patients with low pain levels, ketamine and fentanyl were preferred. During surgery, electrocardiogram, peripheral arterial oxygen saturation and blood pressure were monitored in the operating room. In case of a decrease in oxygen saturation below 95\% during surgery, spontaneous respiration was triggered by manipulation of the anesthesiologist.

The IA group received 4-6 $\mathrm{ml}$ of lidocaine with 1:100.000 adrenaline. This volume of anesthetic was infiltrated percutaneously over the dorsum of the nose leading to bilateral blockage of the infraorbital, infratrochlear and external nasal nerves. The nasal septum was also infiltrated in the submucosal plane. Manipulation took place as soon as the patients lost sensation.

In the TA group, the skin of the nose, ranging from the upper limits of the eyebrows and extending laterally to a vertical line passing through the infraorbital foramen, was cleaned. Thereafter, $2 \mathrm{~g}$ of $5 \%$ lidocaine cream (lidocream, BDderm, Istanbul, Turkey) was applied topically to the inside and outside of the nose. After waiting for the patients to report loss of sensation in the nose (around 15-20 minutes), the surgery was initiated.

\section{Surgical Procedures and Follow-up}

In the SA and IA groups, OR was applied. Hemitransfixion incision and endonasal intercartilaginous incision were carried out according to the site of fracture. Subperiosteal and subperichondrial dissections were carried out to better visualize the fractured bone or the cartilage. The septal fractures were reduced and broken nasal bones were elevated by an elevator under endoscope guidance. After reduction of septal and nasal fracture, the flaps were relocated to their original positions and incisions were sutured.

In the TA group, CR was performed. After the application of anesthesia, the nasal and septal fractures were reduced. The Walsham forceps and elevator were used as septoplasty equipment, and the handle of the scalpel was also used for manual manipulation [4]. A Doyle nasal splint was inserted to both nostrils after the operation and was removed on the third postoperative day [3]. A nasal cast was applied to keep the reduced bones intact, and the cast was removed on the eighth postoperative day.

All patients were followed up for 3 months after having NFR and contacted by telephone for the survey using a 4-point numerical scale. In follow-up visits, nasal patency and cosmetic satisfaction were evaluated by using the same 4-point numerical scale as follows 1: no or least improvement, 2: fair improvement, 3: moderate improvement and 4: maximum improvement.

\section{Pain Assessment and Management}

Visual Analogue Scale (VAS) scores at 0, 12, 24 and 48 hours after surgery, and the amount of analgesic medication required were recorded on the first and fifth days postoperatively. Pain scores were measured for all participants using a VAS from 0 to 10 (0: no pain and 10: severe intolerable pain). Children younger than 7 years of age were graded with the help of their parents. Acetaminophen was prescribed to all patients with a VAS score of $\geq 4$ during the first 24 hours after the surgery. The patients 
were discharged on the next day, and amoxicillin/clavulanate and acetaminophen were prescribed.

\section{Statistical Analysis}

All analyses were performed with the SPSS v15 software (SPSS Inc., Chicago, IL, USA). The Shapiro-Wilk test was used to determine the compliance of variables to normal distribution. Number, percentage, mean, standard deviation (SD), median, minimum and maximum values were used in the depiction of descriptive data. Since, variables did not show normal distribution, continuous data were compared with the KruskalWallis test between the three groups, and post-hoc corrections for pairwise comparisons were performed with the Bonferroni method. Categorical data were compared using Chi-squared test. The threshold for statistical significance was accepted as p-value of $<0.05$.

\section{RESULTS}

This study consisted of 23 (38.3\%) females and 37 (61.7\%) males. The ages of the patients ranged from 2 to 88 years old, with a mean \pm SD value of $23.8 \pm 19.3$ years. The age was significantly lower in the SA group compared to the other two groups $(p<0.001)$, and the age was similar in the IA and TA groups (Table I). Falls was the most common etiology in all three groups $(p=0.001)$. The median duration of operation in the SA group was significantly higher than in the other two groups $(\mathrm{p}<0.001)$. The median reduction time in the SA group was significantly higher than in the IA group $(\mathrm{p}=0.034)$ (Table I). In radiological evaluation, the incidence of septal hematoma was significantly higher in the SA group compared to the other two groups $(\mathrm{p}<0.001)$ (Table II).

Table I. Demograpic characteristics of groups

\begin{tabular}{|c|c|c|c|c|}
\hline \multicolumn{4}{|c|}{ Characteristics } & \multirow[b]{2}{*}{$\mathrm{p}$} \\
\hline & $\begin{array}{l}\text { Sedation anesthesia group } \\
\qquad(\mathrm{n}=20)\end{array}$ & $\begin{array}{l}\text { Infiltrative anesthesia group } \\
\qquad(\mathrm{n}=20)\end{array}$ & $\begin{array}{l}\text { Topical anesthesia group } \\
\qquad(\mathbf{n}=\mathbf{2 0})\end{array}$ & \\
\hline Age & $6.1 \pm 4.0,5(2-17)^{\mathrm{a}}$ & $34.2 \pm 18.8,27.5(15.0-88.0)^{\mathrm{b}}$ & $31.2 \pm 17.0,25.0(15.0-81.0)^{\mathrm{b}}$ & $<0.001^{*}$ \\
\hline \multicolumn{5}{|l|}{ Gender } \\
\hline Female & $7(35.0)$ & $7(35.0)$ & $9(45.0)$ & \multirow[t]{2}{*}{0.754} \\
\hline Male & $13(65.0)$ & $13(65.0)$ & $11(55.0)$ & \\
\hline \multicolumn{5}{|l|}{ Cause of nasal fracture } \\
\hline Falls $^{*}$ & $20(100.0)$ & $6(30.0)$ & $13(65.0)$ & \multirow[t]{5}{*}{$0.001^{*}$} \\
\hline Assault ${ }^{*}$ & $0(0.0)$ & $9(45.0)$ & $5(25.0)$ & \\
\hline Traffic accident & $0(0.0)$ & $3(15.0)$ & $0(0.0)$ & \\
\hline Sports & $0(0.0)$ & $1(5.0)$ & $0(0.0)$ & \\
\hline Work related & $0(0.0)$ & $1(5.0)$ & $2(10.0)$ & \\
\hline Duration of operation & $24.5 \pm 6.3,25.0(15.0-38.0)^{\mathrm{a}}$ & $12.7 \pm 3.3,12.0(9.0-20.0)^{\mathrm{b}}$ & $34.1 \pm 4,7,34.5(29.0-45.0)^{\mathrm{b}}$ & $<0.001^{*}$ \\
\hline Reduction time (day) & $3.9 \pm 2.1,4.0(1.0-7.0)^{\mathrm{a}}$ & $2.3 \pm 1.4,2.0(1.0-5.0)^{\mathrm{b}}$ & $3.0 \pm 1.6,3.0(1.0-6.0)^{\mathrm{ab}}$ & $0.034^{*}$ \\
\hline \multicolumn{5}{|c|}{ Stranc-Robertson classification } \\
\hline Frontal plane $1^{*}$ & $10(50.0)$ & $1(5.0)$ & $4(20.0)$ & \multirow{6}{*}{$0.006^{*}$} \\
\hline Frontal plane 2 & $4(20.0)$ & $2(10.0)$ & $2(10.0)$ & \\
\hline Frontal plane 3 & $0(0.0)$ & $1(5.0)$ & $0(0.0)$ & \\
\hline Lateral plane 1 & $4(20.0)$ & $2(10.0)$ & $5(25.0)$ & \\
\hline Lateral plane $2^{*}$ & $2(10.0)$ & $14(70.0)$ & $9(45.0)$ & \\
\hline Committed & 0 & 3 & 0 & \\
\hline
\end{tabular}

${ }^{*}$ lines that make up the statistical difference $(p<0.05)$

All data are presented as mean ( \pm Standard Deviation).

$a, b$ : same letters depict the lack of significant difference between the denoted groups (columns) in pairwise comparisons.

Table II. Septal fracture and septal hematoma in radiolographic evaluation

\begin{tabular}{|c|c|c|c|c|}
\hline & $\begin{array}{l}\text { Sedation anesthesia group } \\
\qquad(\mathrm{n}=20)\end{array}$ & $\begin{array}{l}\text { Infiltrative anesthesia group } \\
\qquad(\mathrm{n}=20)\end{array}$ & $\begin{array}{l}\text { Topical anesthesia group } \\
\qquad(\mathrm{n}=20)\end{array}$ & p \\
\hline \multicolumn{5}{|c|}{ Septal fracture } \\
\hline Absent & $0(0.0)$ & $2(10.0)$ & $2(10.0)$ & \multirow[t]{2}{*}{0.343} \\
\hline Present & $20(100.0)$ & $18(90.0)$ & $18(90.0)$ & \\
\hline \multicolumn{5}{|c|}{ Septal hematoma } \\
\hline Absent & $0(0.0)$ & $18(90.0)$ & $20(100.0)$ & \multirow[t]{2}{*}{$<0.001^{*}$} \\
\hline Present & $20(100.0)$ & $2(20.0)$ & $0(0.0)$ & \\
\hline
\end{tabular}

* lines that make up the statistical difference $(p<0.05)$ 
The immediate postoperative VAS scores $(0 \mathrm{hrs})$ of the group that underwent NFR with IA was significantly lower than the other two groups $(p=0.001)$. The median VAS scores immediately after surgery in the SA and TA groups were found to be similar. VAS scores at the 12th hour $(\mathrm{p}=0.004)$ and the 24 th hour $(\mathrm{p}<0.001)$ were found to be significantly higher in the SA group compared to the other two groups. In contrast, the median VAS score at 48 hours was lower in the TA group compared to the other groups $(\mathrm{p}=0.016$, Table III).

The SA, IA and TA groups were found to be similar in terms of perceived satisfaction with nasal patency $(\mathrm{p}=0.073)$ (Table IV). Cosmetic satisfaction levels of the three groups differed significantly $(\mathrm{p}<0.001)$. Satisfaction was highest in the SA group, followed by the IA group (Table V).

Table III. Comparison of VAS pain scores between groups immediately after surgery, at 12 hours, 24 hours and 48 hours

\begin{tabular}{|c|c|c|c|c|}
\hline & $\begin{array}{l}\text { Sedation anesthesia } \\
\text { Mean } \pm \text { SD } \\
\text { Median (Min-Max) }\end{array}$ & $\begin{array}{c}\text { Infiltrative anesthesia } \\
\text { Mean } \pm \text { SD } \\
\text { Median (Min-Max) }\end{array}$ & $\begin{array}{c}\text { Topical anesthesia } \\
\text { Mean } \pm \text { SD } \\
\text { Median (Min-Max) }\end{array}$ & $\mathbf{p}$ \\
\hline Postoperative at 0 hour (at PACU) & $\begin{array}{c}2.6 \pm 1.1 \\
2.5(1.0-6.0)^{\mathrm{a}} \\
\end{array}$ & $\begin{array}{c}1.5 \pm 0.8 \\
2.0(0.0-3.0)^{\mathrm{b}}\end{array}$ & $\begin{array}{c}2.2 \pm 0.6 \\
2.0(1.0-3.0)^{\mathrm{a}} \\
\end{array}$ & $0.001^{\star}$ \\
\hline Postoperative at 12 hours & $\begin{array}{c}6.8 \pm 0.7 \\
7.0(6.0-8.0)^{\mathrm{a}}\end{array}$ & $\begin{array}{c}6.1 \pm 1.1 \\
6.0(4.0-9.0)^{\mathrm{b}}\end{array}$ & $\begin{array}{c}6.0 \pm 0.8 \\
6.0(4.0-7.0)^{\mathrm{b}}\end{array}$ & $0.004^{*}$ \\
\hline Postoperative at 24 hours & $\begin{array}{c}6.9 \pm 0.6 \\
7.0(6.0-8.0)^{\mathrm{a}} \\
\end{array}$ & $\begin{array}{c}5.7 \pm 0.8 \\
6.0(4.0-7.0)^{\mathrm{a}} \\
\end{array}$ & $\begin{array}{c}5.2 \pm 0.8 \\
5.0(3.0-6.0)^{\mathrm{b}}\end{array}$ & $<0.001^{*}$ \\
\hline Postoperative at 48 hours & $\begin{array}{c}4.8 \pm 0.8 \\
5.0(3.0-6.0)^{\mathrm{a}}\end{array}$ & $\begin{array}{c}4.9 \pm 1.0 \\
5.0(3.0-6.0)^{\mathrm{a}} \\
\end{array}$ & $\begin{array}{c}4.1 \pm 0.8 \\
4.0(3.0-6.0)^{\mathrm{b}} \\
\end{array}$ & $0.016^{*}$ \\
\hline
\end{tabular}

PACU: Postanesthetic Care Unit, VAS: Visual Analogue Scale

* lines that make up the statistical difference $(p<0.05)$

$a, b$ : same letters depict the lack of significant difference between the denoted groups (columns) in pairwise comparisons.

Table IV. Distribution of satisfaction levels of nasal patency among anesthesia groups

\begin{tabular}{|c|c|c|c|c|}
\hline & $\begin{array}{c}\text { Sedation anesthesia group } \\
\mathbf{n}(\%)\end{array}$ & $\begin{array}{l}\text { Infiltrative anesthesia group } \\
\mathrm{n}(\%)\end{array}$ & $\begin{array}{l}\text { Topical anesthesia group } \\
\mathrm{n}(\%)\end{array}$ & p \\
\hline No or least improvement & $2(10.0)$ & $1(5.0)$ & $1(5.0)$ & \multirow{4}{*}{0.073} \\
\hline Fair improvement & $0(0.0)$ & $2(10.0)$ & $5(25.0)$ & \\
\hline Moderate improvement & $3(15.0)$ & $3(15.0)$ & $7(35.0)$ & \\
\hline Maximum improvement & $15(75.0)$ & $14(70.0)$ & $7(35.0)$ & \\
\hline
\end{tabular}

Table V. Distribution of cosmetic satisfaction levels among anesthesia groups

\begin{tabular}{lcccc} 
& $\begin{array}{c}\text { Sedation anesthesia group } \\
\mathbf{n}(\%)\end{array}$ & $\begin{array}{c}\text { Infiltrative anesthesia group } \\
\mathbf{n}(\%)\end{array}$ & $\begin{array}{c}\text { Topical anesthesia group } \\
\mathbf{n}(\%)\end{array}$ & $\mathbf{p}$ \\
\hline No or least improvement & $2(10.0)$ & $1(5.0)$ & $1(5.0)$ & $6(30.0)$ \\
Fair improvement & $0(0.0)$ & $1(5.0)$ & $8(40.0)$ & $<0.001^{*}$ \\
Moderate improvement $_{\text {Maximum improvement }}^{*}$ & $4(20.0)$ & $6(30.0)$ & $5(25.0)$ \\
\hline
\end{tabular}

* lines that make up the statistical difference $(p<0.05)$

\section{DISCUSSION}

The demographic characteristics of patients with NF vary according to many factors, including geographic region, culture, religion and economic status [11]. Statistically, there was no gender-based difference in the distribution of NF. However, there was a male dominance in our study overall, similar to that reported by Chadha et al., who had a male-to-female ratio greater than $2: 1$. The highest incidences were seen in two age groups, in patients aged 15-30 years and in the elderly, in relation to the incidence of falls. The majority of nasal fractures in young adults were due to assault, sports and motor vehicle accidents [12]. In the hospital, which is in the South-Eastern region of Turkey, falls were the most common etiology in patients who underwent SA and TA; whereas assault was the most common cause in the IA group. In prior studies, it had been reported that assault and motor accident-related cases were more common in adults, while falls were more common in children [13]. In our study, operation time was longer in the SA group with a 
mean \pm standard deviation of $24.5 \pm 6.3 \mathrm{~min}$ because of the longer duration of anesthesia and duration of OR. In a study conducted by Kyung CR, duration of operation was 17.06 mins with SA and 20.29 mins in GA [8]. In Cook et al.s study, either IA or blocks of the intraorbital/infratrochlear nerves, the CR surgeries took between 15-30 mins [14] and time between injury and operation

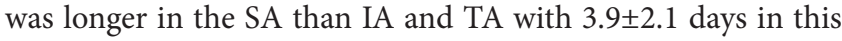
study $(\mathrm{p}<0.05)$. The time between injury and operation was 6.8 days, according to Kim et al. [15].

Physical examination is not adequate to diagnose the complexity and details of NF. 25\% of NFs that require surgery are negative in radiologic investigations. Although, CT scan can precisely show anatomic details of nasal bone and soft tissue, it carries risk for the lens of the eye especially in children [16]. In this study, CT images of the patients with NFs were evaluated in order to rule out other indications such as brain trauma as well as eye and skull trauma. Septal fractures are generally unrecognized and untreated in most of NF cases. Rhee et al., diagnosed septal fracture in $96.2 \%$ of NFs by CT examination [17]. In this study, septal fractures were present in $100 \%$ of the SA group, in $90 \%$ of the IA group and in $90 \%$ of the TA group, as determined by CT examination (Fig 1). Nasal septal hematoma (Fig 2), seen in $0.8-1.6 \%$ of NF cases is particularly more common in the pediatric population because the mucoperichondrium is loosely adherent to the underlying cartilage. Septal hematoma without any sequelae was mentioned by Alverez et al., similar to the results of the current study. We observed tomographic evidence of septal hematoma without any physical finding. It has been demonstrated that medical intervention is necessary in the presence of septal hematoma diagnosed by physical examination [18]. In this study, hematomas observed in 2 patients on physical examination were aspirated after performing a hemitransfixion incision under SA. As a result, advantages and disadvantages of performing CT should be carefully evaluated by the physician.

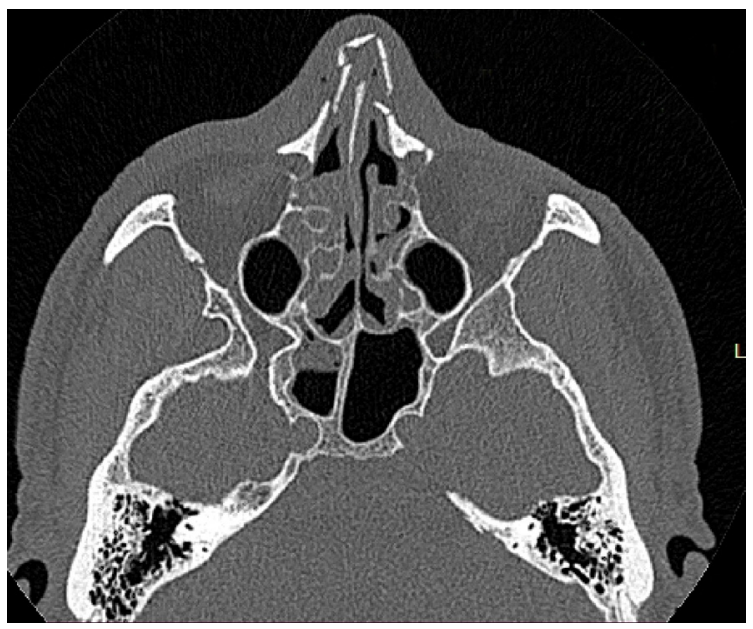

Figure 1. CT image of a 55-year-old man after physical assault. Note nasal septal fracture and nasal bone fracture; Stranc-Robertson classification $C$ treated under infiltration anesthesia

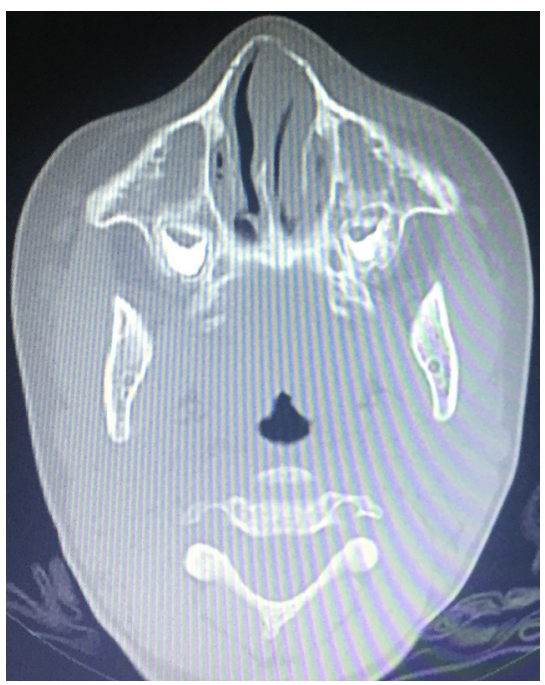

Figure 2. CT image of a 5-year-old boy who fell down. Note septal fracture, minimal septal hematoma and nasal bone fracture. Stranc-Robertson classification F2

Nasal fracture reduction procedures cause pain during and after surgery [19]. Atighechi et al., in their comparative study of CR procedures found that mean pain score was 2.35 in TA group, 2.47 in IA group, and 1.9 in GA group, and these were statistically nonsignificant among the groups [20]. In this current study, immediate postoperative VAS scores were lowest in the IA group (1.5 \pm 0.8$)$. VAS scores at 12 hours were $(6.8 \pm 0.7)$ and at 24 hours it was $(6.9 \pm 0.6)$. These scores were found to be significantly higher than those in the SA group because OR of NF was carried out in SA group and this was expected to be more painful. In OR, septoplasty or rhinoplasty were performed to reach the septum or nasal bones for direct visualization [3]. VAS scores at 48 hours showed that pain was lowest in the TA group $(4.1 \pm 0.8)$ as the TA group had CR. Sclafani et al,, in their study of postoperative pain in septoplasty and rhinoplasty, found that the pain reported for septoplasty was 0-78 and pain reported for rhinoplasty was 0-88 on scale of 100 by VAS scale [21]. According to a study, less pain was felt by using general lidocaine anesthesia than using topical lidocaine and lidocaine infiltration at 6 hours in CR [22].

Perceived satisfaction in NF can be affected by the type of treatment and anesthesia choice. In the past studies, satisfaction with NF performed by CR is reported as $90 \%$ [20]. Satisfaction level was $98 \%, 100 \%$, and $71 \%$ in studies conducted by Ridder et al., Ondik et al., Hung et al., respectively $[23,5,24]$. In a study by Murray and Marran, failure rate was $32.5 \%$ and Yilmaz et al., found that satisfaction level after 6 month of CR was 65\% [25]. Atighechi et al., in their comparative study of GA, IA and TA+IA in NFs, found that satisfaction among groups were statistically similar [20]. In this study, nasal patency satisfaction was similar among all groups ( $p>0.05$ ) with maximum improvement of $75 \%$ in SA, $70 \%$ in IA and $35 \%$ in TA. In contrast, cosmetic satisfaction was significantly different between groups $(\mathrm{p}<0.01)$. Cosmetic satisfaction with maximum improvement was $70 \%$ in SA, $60 \%$ 
in IA and $25 \%$ in TA group. In a study by Rajapakse et al., there was no statistical significance between TA+IA and GA groups in terms of cosmetic satisfaction and nasal function. The study also found $86 \%$ satisfaction with nasal patency, $84 \%$ in cosmesis in either GA or TA+IA [26]. In CR under LA 78\% functional satisfaction and $69.5 \%$ cosmetic satisfaction were found by Vilela et al. [27]. In this current study more favorable results in both nasal patency and cosmetic satisfaction were found in SA group because of OR (Figures 3A, 3B, 3C).

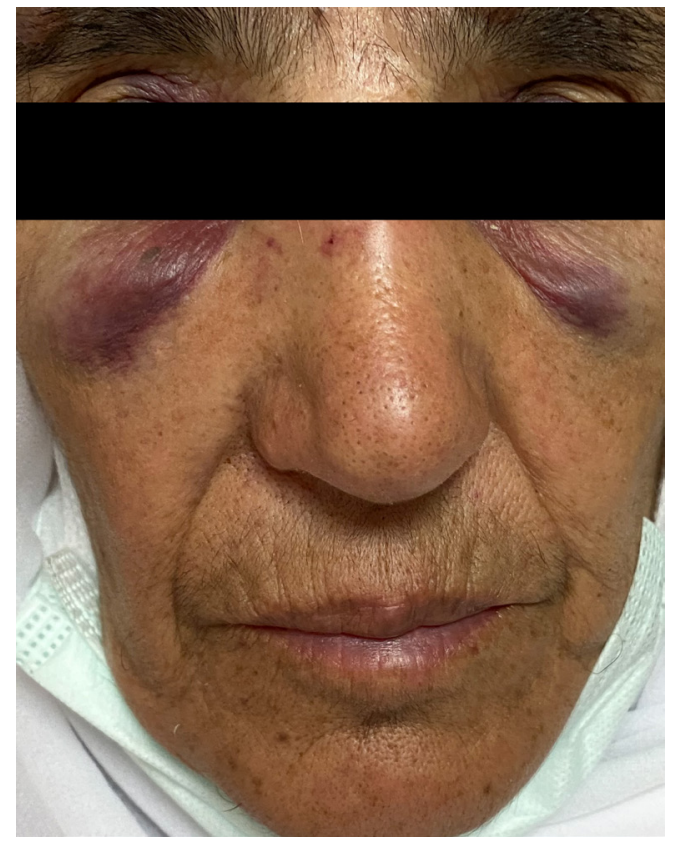

Figure 3A. A 63-year-old female who fell down. Nasal axis deviation before she underwent $C R$ (closed reduction) under local anesthesia

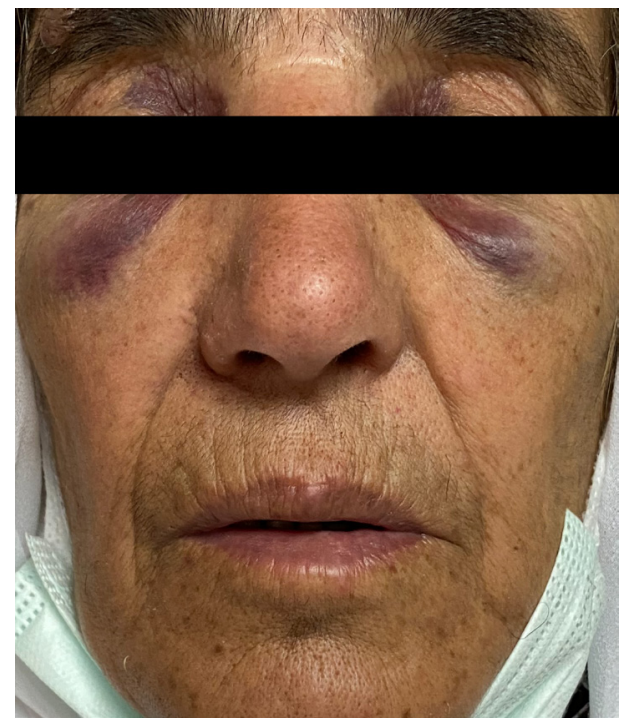

Figure 3B. Following CR, disapperance of axis deviation

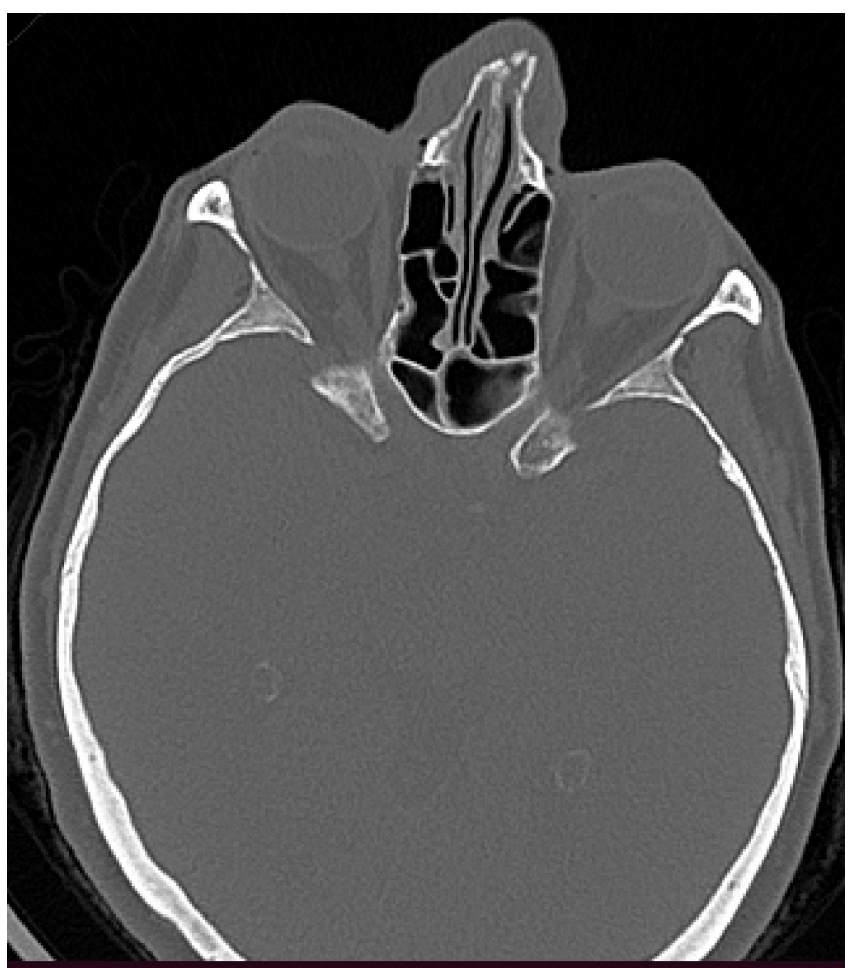

Figure 3C. CT image with nasal axis deviation to the left before CR. Stranc-Robertson classification L2

This current study is a descriptive study that provides an overview of daily practice in ENT clinic about NF, the demographic characteristics, level of pain and satisfaction of patients and the radiologic details of fractures. Small sample size, lack of standardization in terms of age and treatment options (CR/ OR) among groups and assessment of pain and satisfaction of children by parents were limitations of this study. Although, this study provides an idea about the level of pain and satisfaction, exact evaluation of pain and satisfaction was not obtained from the results. We performed OR in the SA and IA groups, while CR was utilized in the TA group. Also, there are methodological difficulties in comparing pain and satisfaction between patients receiving TA, IA and SA. For instance, SA recipients will be unconscious during the procedure, and therefore, only post procedural pain can truly be assessed. There may also be a tendency for patients to attribute surrogate outcomes to their SA, such as pain on insertion of intravenous cannulae, splints, post-operative nausea or vomiting, or other post-operative symptoms. In accepting these limitations, we decided to provide an overview of NF treatments; OR vs CR and the level of pain and satisfaction among two treatment options with SA, IA and TA groups. However, it is rather evident that anesthesia approach and type of reduction surgeries may vary in different hospital settings, patient characteristics, and the surgeons. Other studies should be conducted with the inclusion of different settings and different properties. 


\section{Conclusion}

Nasal fractures can be efficiently and comfortably treated with SA in children. IA and TA are mostly applied in adults. Tomographic evaluation of NF provides detailed assessment especially in septal fracture and hematoma, mostly seen in children which requires surgical intervention but radiation hazards should be kept in mind. Additionally, although immediate effects on pain appear to be insufficient with TA, later pain results show favorable effects and is ideal preference when cosmetic expectation is low; whereas, immediate pain alleviation is better with IA. Cosmetic satisfaction was highest with SA in which OR was performed in our study. Although, choice of anesthesia and treatment are multifactorial depending on surgeon preference, hospital circumstances and patient characteristics, additional studies are needed to enrich the literature about NF to reach more standardized applications in anesthesia.

Acknowledgements: I would like to thank my colleagues, anesthesiologists and nursing staff for their kind cooperation and support throughout this study.

\section{Compliance with Ethical Standards}

Ethical Approval: The study was conducted in accordance with the ethical principles stated in the Declaration of Helsinki and was approved by the Ethics Committee for Clinical Research at Gazi Yasargil Education and Research Hospital (protocol no: 2019/392). Institutional ethics committee approval was obtained before commencing to collect the data. Written informed consent was obtained from all participants before NFR. Patients also gave their consent for images relating to their cases to be reported in a medical publication.

Conflict of Interest The author declare no potential conflicts of interest with respect to the research, authorship, and/or publication of this article.

Financial Support: The author received no financial support for the research, authorship, and/or publication of this article.

\section{REFERENCES}

[1] Al-Moraissi EA, Ellis E III. Local versus general anesthesia for the management of nasal bone fractures: a systematic review and meta-analysis. J Oral Maxillofac Surg 2015 ;73:606-15. doi: 10.1016/j.joms.2014.10.013.

[2] Cohn JE, Othman S, Toscano M, Shokri T, Bloom JD, Zwillenberg S. Nasal bone fractures: Differences amongst sub-specialty consultants. Ann Otol Rhinol Laryngol 2020; 129:1120-8. doi: 10.1177/000.348.9420931562.

[3] Lu GN, Humphrey CD, Kriet JD. Correction of nasal fractures. Facial Plast Surg Clin North Am 2017 ;25:537-46. doi: 10.1016/j.fsc.2017.06.005.

[4] Ichida M, Komuro Y, Koizumi T, Shimizu A, Yanai A. A repositioning technique for nasal fracture using the little finger. J Craniofac Surg 2008 ;19:1512-7. doi: 10.1097/ SCS.0b013e31818b37e0.

[5] Ondik MP, Lipinski L, Dezfoli S, Fedok FG. The treatment of nasal fractures: a changing paradigm. Arch Facial Plast Surg 2009 ;11:296-302. doi: 10.1001/archfacial.2009.65
[6] Ortega A, Gauna F, Munoz D, Oberreuter G, Breinbauer HA, Carrasco L. Music therapy for pain and anxiety management in nasal bone fracture reduction: Randomized controlled clinical trial. Otolaryngol Head Neck Surg 2019 ;161:613-9. doi: 10.1177/019.459.9819856604.

[7] Coté CJ, Wilson S. Guidelines for monitoring and management of pediatric patients before, during, and after sedation for diagnostic and therapeutic procedures. Pediatr Dent 2019; 41:26E-52E.

[8] Kyung H, Choi JI, Song SH, Oh SH, Kang N. Comparison of postoperative outcomes between monitored anesthesia care and general anesthesia in closed reduction of nasal fracture. J Craniofac Surg 2018 ;29:286-8. doi: 10.1097/ SCS.000.000.0000004084.

[9] Park KS, Kim SS, Lee WS, Yang WS. The Algorithm-oriented management of nasal bone fracture according to stranc's classification system. Arch Craniofac Surg 2017 ;18:97-104. doi: 10.7181/acfs.2017.18.2.97.

[10] Butterworth JF, Mackey D C, Wasnick J D, (Eds). Morgan and Michail's Clinical Anesthesiology, 5e.New York: McGraw-Hill, 2013.

[11] Hwang K, Ki SJ, Ko SH. Etiology of nasal bone fractures. J Craniofac Surg 2017 ;28:785-8. doi: 10.1097/ SCS.000.000.0000003477.

[12] Chadha NK, Repanos C, Carswell AJ. Local anaesthesia for manipulation of nasal fractures: systematic review. J Laryngol Otol 2009 ;123:830-6. doi: 10.1017/S002.221.510900560X.

[13] Yu H, Jeon M, Kim Y, Choi Y. Epidemiology of violence in pediatric and adolescent nasal fracture compared with adult nasal fracture: An 8-year study. Arch Craniofac Surg 2019; 20:228-32. doi: 10.7181/acfs.2019.00346.

[14] Cook JA, Murrant NJ, Evans K, Lavelle RJ. Manipulation of the fractured nose under local anaesthesia. Clin Otolaryngol Allied Sci 1992 ;17:337-40. doi: 10.1111/j.1365-2273.1992. tb01008.x.

[15] Kim HS, Lee HK, Jeong HS, Shin HW Decreased postoperative pain after reduction of fractured nasal bones using a nerve block of the anterior ethmoidal nerve. Int J Oral Maxillofac Surg 2013 ;42:727-31. doi: 10.1016/j.ijom.2013.01.017.

[16] Mohammadi A, Ghasemi-Rad M. Nasal bone fractureultrasonography or computed tomography? Med Ultrason $2011 ; 13: 292-5$. PMID: 22132401.

[17] Rhee SC, Kim YK, Cha JH, Kang SR, Park HS. Septal fracture in simple nasal bone fracture. Plast Reconstr Surg 2004; 113:45-52. doi: 10.1097/01.PRS.000.009.6705.64545.69

[18] Sayin I, Yazici ZM, Bozkurt E, Kayhan FT. Nasal septal hematoma and abscess in children. J Craniofac Surg 2011; 22:e17-9. doi: 10.1097/SCS.0b013e31822ec801.

[19] Ayatollahi V, Vafaiyan M, Hatami M, Behdad S. Two different concentrations of ketofol for procedural sedation and analgesia in closed reduction of nasal fracture. J Craniofac Surg 2016; 27:996-1000. doi: 10.1097/SCS.000.000.0000002660.

[20] Atighechi S, Baradaranfar MH, Akbari SA. Reduction of nasal bone fractures: a comparative study of general, local, and 
topical anesthesia techniques. J Craniofac Surg 2009; 20:382-4. doi: 10.1097/SCS.0b013e31819b945f.

[21] Sclafani AP, Kim M, Kjaer K, Kacker A, Tabaee A. Postoperative pain and analgesic requirements after septoplasty and rhinoplasty. Laryngoscope. 2019 ;129:2020-5. doi:10.1002/ lary.27913.

[22] Zhu J, Liu J, Shen G, Zhong T, Yu X. Comparison of efficacy outcomes of lidocaine spray, topical lidocaine injection, and lidocaine general anesthesia in nasal bone fractures surgeries: A randomized, controlled trial. Med Sci Monit 2018 ;24:438694. doi:10.12659/MSM.908468.

[23] Ridder GJ, Boedeker CC, Fradis M, Schipper J. Technique and timing for closed reduction of isolated nasal fractures: a retrospective study. Ear Nose Throat J 2002;81:49-54.
[24] Hung T, Chang W, Vlantis AC, Tong MC, van Hasselt CA. Patient satisfaction after closed reduction of nasal fractures. Arch Facial Plast Surg 2007;9:40-3 doi: 10.1001/archfaci.9.1.40.

[25] Yilmaz MS, Guven M, Varli AF. Nasal fractures: is closed reduction satisfying? J Craniofac Surg 2013; 24:e36-8. doi: 10.1097/SCS.0b013e3182688ea1.

[26] Rajapakse Y, Courtney M, Bialostocki A, Duncan G, Morrissey G. Nasal fractures: a study comparing local and general anaesthesia techniques. ANZ J Surg 2003 ;73:396-9. doi: 10.1046/j.1445-2197.2003.t01-1-02615.x.

[27] Vilela F, Granjeiro R, Maurício C Júnior, Andrade P. Applicability and effectiveness of closed reduction of nasal fractures under local anesthesia. Int Arch Otorhinolaryngol 2014; 18:266-71. doi: 10.1055/s-0034.136.8138. 